\title{
Efek Penambahan Nanoselulosa Terhadap Compressive strength Bone cement Berbasis Kalsium Fosfat
}

\author{
Fadly CC ${ }^{1}$, Evelyna $\mathrm{A}^{1}$, Bambang Sunendar P.*** \\ 1. Falkutas Kedokteran Gigi, Universitas Kristen Maranatha, 40164, Indonesia \\ Email: eveline.cindy@yahoo.com
}

\begin{abstract}
Abstrak
Bone cement kalsium fosfat merupakan generasi terbaru material pengganti tulang. Semen ini menghasilkan hidroksiapatit yang memiliki struktur kimia dan morfologi komponen dasar yang menyerupai tulang sehingga bone cement dapat digunakan untuk memfiksasi implan gigi immediate loading dental implan yang memiliki beberapa keuntungan. Namun sifat mekanisnya rendah sehingga perlu ditambah filler agar sifat mekanisnya meningkat

Penelitian ini bersifat eksperimental laboratorium dan dilakukan untuk membuat bone cement dengan alginat sebagai matriks yang ditambahkan nanoselulosa kristalin dan kalsium fosfat hidroksiapatit sebagai filler. Filler nanoselulosa kristalin disintesis dengan hidrolisis asam kemudian dikarakterisasi menggunakan TEM dan XRD. Pengujian sifat mekanis yang dilakukan yaitu uji tekan kompresi. Analisis dilakukan dengan ANOVA one way, dilanjutkan dengan Post Hoc Tuckey.

Hasil uji tekan kompresi memperlihatkan kompresi tertinggi pada kelompok V (nanoselulosa 2\%) sebesar 8,161 Mpa.

Kesimpulan pada penelitian ini adalah penambahan filler nanoselulosa kristalin pada bone cement berbasis kalsium fosfat meningkatkan compressive strength.
\end{abstract}

\section{The Effect of Adding Nanocellulose on Compressive Strength of Bone Cement That Based on Calcium Phosphate}

\begin{abstract}
Calcium Phosphate Bone cement is the newest generation of replacement bone material. This cement produces hydroxyapatite which has a chemical structure and morphology of bone-like basic components so that a bone cement can be used to fix immediate loading dental implant which has several advantages. However, the mechanical properties are low so fillers need to be added to increase the mechanical properties.

This study was an experimental laboratory and carried out to make bone cement with alginate as a matrix added to crystalline nanocellulose and calcium phosphate hydroxyapatite as fillers. Crystalline nanocellulose fillers was synthesized by acid hydrolysis were then characterized using TEM and XRD. Testing of mechanical properties is done by compressive compression test. The analysis was carried out with one way ANOVA, followed by Post Hoc Tuckey.

This compressive compression test result showed the highest compression in group $V(2 \%$ nanocellulose $)$ of
\end{abstract}




\subsection{Mpa.}

The conclusion of this study is the addition of crystalline nanocellulose fillers in calcium phosphate based bone cement to increase compressive strength.

Keywords: bone cement; compressive strength; kalsium fosfat; nanoselulosa kristalin

\section{Pendahuluan}

Saat ini, teknologi dental implan semakin berkembang. Hal ini mendorong dokter gigi untuk merekomendasikan dental implan sebagai perawatan rehabilitasi dalam menggantikan gigi yang hilang karena dental implant memberikan berbagai keunggulan dalam hal kestabilan dan kenyamanan dibandingkan gigi tiruan. Dental implant yang tersedia salah satu nya adalah immediate loading implant. Disamping itu, pengetahuan tentang bone cement atau polymethylmethacrylate (PMMA) sangat penting bagi semua ahli bedah maksilofasial, fiksasi implan gigi immediate loading dental implan yang memiliki keuntungan seperti penghematan waktu dan biaya perawatan, trauma jaringan yang lebih sedikit, hasil estetik yang optimal, menurunkan kecemasan dan ketidaknyamanan bagi pasien, dan memudahkan posisi saat pemasangan implan. ${ }^{1,2}$ Bone cement adalah bahan pengisi yang digunakan untuk menahan implan dengan tulang. Jenis lain dari bone cement yang tersedia secara komersial seperti semen kalsium fosfat (CPC) dan Glass polyalkenoate (ionomer) semen (GPC) telah berhasil digunakan dalam berbagai aplikasi ortopedi dan gigi. Kelebihan semen tulang (bone cement) dengan basis PMMA adalah kemampuannya yang mudah dibentuk sehingga dapat menghasilkan bentuk yang rumit sekalipun, selain itu juga dapat berfungsi sebagai pengisi (filler), dan memiliki sifat biokompatibilitas yang paling baik diantara jenis material polimer lainnya namun, bone cement berbasis PMMA memiliki keterbatasan yaitu tidak memiliki sifat bone bonding karena PMMA tidak memiliki lapisan apatit yang dapat berikatan dengan tulang. 3,4

Penelitian mengenai bahan bone cement terus berkembang untuk memperbaiki limitasi bone cement berbasis PMMA, hingga akhirnya pada sekitar tahun 1980 Brown-Chow menemukan bone cement berbasis kalsium fosfat yang merupakan dua komponen dasar penyusunan tulang, yang lebih dikenal dengan calcium phosphate cement (CPC). Bone cement berbasis kalsium fosfat juga banyak digunakan dalam aplikasi kedokteran. Selain itu, kelebihan dari CPC adalah kemampuan mengeras sendiri (self-hardening), osteokonduktif, biokompatibilitas, bioresorbabel dan mudah dibentuk membuat CPC menjadi material yang unik untuk memperbaiki tulang yang rusak. Sifat nontoksik dan non karsinogenik membuat pemakaian CPC lebih disarankan daripada PMMA tetapi jenis CPC memiliki keterbatasan yaitu tidak dapat menahan beban yang tinggi karena memiliki kekuatan atau sifat mekanik yang rendah. 4

Compressive strength suatu material kedokteran gigi dapat diketahui dengan menggunakan uji in vitro compressive strength yang telah direkomendasikan sesuai standar Internasional yaitu ISO 4049/2000 untuk menguji material berbasis polimer. 5

Saat ini juga sedang dikembangkan sebuah material baru untuk bahan baku material restorasi kedokteran gigi seperti nanoselulosa. Nanoselulosa merupakan material yang alami dan memiliki karakteristik unik dan disintesis dari selulosa (didapat 
dari tumbuhan, hewan dan bakteri). Nanoselulosa memiliki beberapa aplikasi dalam bidang kesehatan. Aplikasi tersebut adalah kultur jaringan, pengobatan, penyembuhan luka, dan material antibakteri. 6

Nanoselulosa yang dipakai untuk penelitian ini adalah nanoselulosa kristalin yang diekstrak dengan reaksi kimia seperti hidrolisis asam, yang biasa digunakan untuk megekstraksi nanoselulosa kristalin dari selulosa murni dengan menghilangkan bagian amorf dan menyisakan struktur kristalin yang tinggi, oleh karena itu penulis tertarik untuk melakukan uji compressive strength dengan penambahan nanoselulosa pada bone cement berbasis kalsium fosfat. 6

Identifikasi masalah penelitian ini adalah apakah penambahan nanoselulosa pada bone cement berbasis kalsium fosfat dapat mempengaruhi compressive strength.

Tujuan penelitian ini adalah untuk mengetahui apakah terdapat efek penambahan nanoselulosa pada bone cement berbasis kalsium fosfat terhadap compressive strength.

\section{Metode Penelitian}

Alat yang digunakan dalam penelitian ini: cetakan semen, penggaris, pipet tetes, spatula semen, timbangan digital dan rubber bowl. Bahan yang digunakan dalam penelitian ini: aquades, hidroksiapatit, kitosan, nanoselulosa kristalin, dan alginat.

Penelitian yang akan dilakukan adalah penelitian eksperimental laboratorium yang dibagi menjadi Kelompok I (bone cement berbasis kalsium fosfat tanpa penambahan nanoselulosa kristalin), Kelompok II (bone cement berbasis kalsium fosfat dengan penambahan nanoselulosa kristalin 0.5\%), Kelompok III (bone cement berbasis kalsium fosfat dengan penambahan nanoselulosa kristalin 1\%), Kelompok IV (bone cement berbasis kalsium fosfat dengan penambahan nanoselulosa kristalin 1.5\%), Kelompok V (bone cement berbasis kalsium fosfat dengan penambahan nanoselulosa kristalin $2 \%$ ). Jumlah sampel pada penelitian sebanyak 25 sampel. Siapkan sodium alginate sebanyak 0,84 gram, kalsium fosfat sebanyak 1 gram (setiap penambahan nanoselulosa, kalsium fosfat dikurangi sebanyak nanoselulosa yang ditambahkan)(cth: pada nanoselulosa 0,5\% maka banyaknya kalsium fosfat adalah dan banyaknya nanoselulosa 0,995 gram adalah 0,005 gram. Pengujian dilakukan dengan mengaduk bubuk secara rata kemudian diteteskan larutan kitosan 1\% sebanyak 65 tetes kemudian spesimen diaduk secara merata dengan spatula semen dan spesimen semen dicetak pada piringan specimen dengan ukuran $(4 \pm 0,1)$ pada diameter dan $(8 \pm 0,1)$ pada tinggi kemudian spesimen semen dimasukan kedalam oven dengan suhu $37^{\circ} \mathrm{C}$ selama 24 jam setelah

24 jam spesimen dikeluarkan dari cetakan dan kemudian spesimen siap diuji. Variabel penelitian dibagi menjadi tiga kelompok yaitu variabel bebas, yakni nanoselulosa kristalin dan kalsium fosfat; sedangkan variabel terikatnya, yakni compressive strength; dan variabel kontrol, yakni bone cement kalsium fosfat hidroksiapatit tanpa penambahan kalsium fosfat.

Analisis data dilakukan dengan menggunakan analisis statistik ANOVA one way dilanjutkan dengan menggunakan program komputer SPSS dan Post Hoc Tuckey yaitu untuk melihat perbedaan pengaruh kelompok 1,2,3,4, dan 5 . 


\section{Hasil Penelitian}

Hasil penelitian ini terdiri dari hasil karakterisasi morfologi partikel filler, hasil uji compression test. Karakterisasi partikel filler menggunakan Transmission Electron Microscope (TEM) dengan mesin Hitachi HT7700 untuk nanoselulosa kristalin dan X-Ray Diffraction (XRD) dengan mesin Bruker D8 Advance. Uji compressive strength menggunakan mesin uji Shimadzu Autograph AGS_5kNx dan dianalisa menggunakan software TrapeziumX.

Hasil dan Analisis Karakterisasi Filler

Filler yang digunakan pada penelitian ini adalah nanoselulosa kristalin. Nanoselulosa kristalin dikarakterisasi menggunakan Transmission Electron Microscope (TEM) dan X-Ray Diffraction (XRD).

- Hasil karakterisasi Transmission Electron Microscope (TEM) Nanoselulosa Kristalin Hasil karakterisasi TEM pada gel bahan pengisi nanoselulosa menunjukkkan morfologi partikel yang terbentuk adalah nanowhisker, dimana spesimen nanoselulosa berbentuk seperti batangan jerami (whisker) dengan kisaran ukuran panjang bervariasi antara $134 \mathrm{~nm}$ sampai $407 \mathrm{~nm}$. Pada gambar dengan perbesaran 15.000 kali dan 30.000 kali, terlihat bahwa persebaran nanowhisker merata.

- Hasil Karakterisasi X-Ray Diffraction (XRD) Nanoselulosa Kristalin Hasil analisis difaktogram menggunakan software diffract menunjukkan bahwa terdapat tiga titik puncak tertinggi, puncak pertama dimulai pada $23,5^{\circ}$ yang merupakan puncak difraksi terendah, lalu puncak tertinggi ditunjukkan pada $31,9^{\circ}$ dan bergeser pada $34^{\circ}$. Tiga titik puncak difraksi berkisar $23,5^{\circ}-34^{\circ}$, hal ini menunjukkan kesesuaian angka difraksi nanoselulosa dari penelitian Nilsson (2017) dimana hasil XRD nanoselulosa berkisar antara $12,3^{\circ}-34,7^{\circ}$ menggambarkan puncak difraksi.

Hasil Uji dan Analisis Uji Compressive strength

Uji compressive strength dilakukan pada 25 spesimen yang dibagi menjadi 5 kelompok, yaitu kelompok I (CPC tanpa adanya penambahan nanoselulosa), kelompok II (CPC dengan penambahan nanoselulosa 0,5\%), kelompok III (CPC dengan penambahan nanoselulosa 1\%), kelompok IV (CPC dengan penambahan nanoselulosa 1,5\%), kelompok $\mathrm{V}$ (CPC dengan penambahan nanoselulosa 2\%) menggunakan mesin uji Shimadzu Autograph AGS-5kNx dengan kecepatan crosshead $1 \mathrm{~mm} /$ menit, dan beban $1 \mathrm{kN}$. Hasil uji compressive strength dapat dilihat ada tabel berikut:

Tabel I Hasil Uji Compressive strength (MPa)

\begin{tabular}{llllll}
\hline \multirow{2}{*}{ No. Sampel } & \multicolumn{5}{c}{ Kelompo } \\
\cline { 2 - 6 } & I & II & III & IV & V \\
\hline 1 & 3.742 & 5.512 & 5.737 & 6.736 & 8.782 \\
\hline 2 & 4.439 & 5.609 & 5.745 & 6.459 & 7.928 \\
\hline 3 & 3.966 & 4.439 & 5.650 & 6.206 & 8.223 \\
\hline 4 & 4.704 & 3.966 & 6.749 & 6.520 & 7.691 \\
\hline 5 & 4.985 & 4.985 & 5.974 & 7.054 & 8.182 \\
\hline Rerata & 4.367 & 4.902 & 5.971 & 6.595 & 8.161 \\
\hline
\end{tabular}


Berikut adalah diagram batang hasil uji Three point Bending:

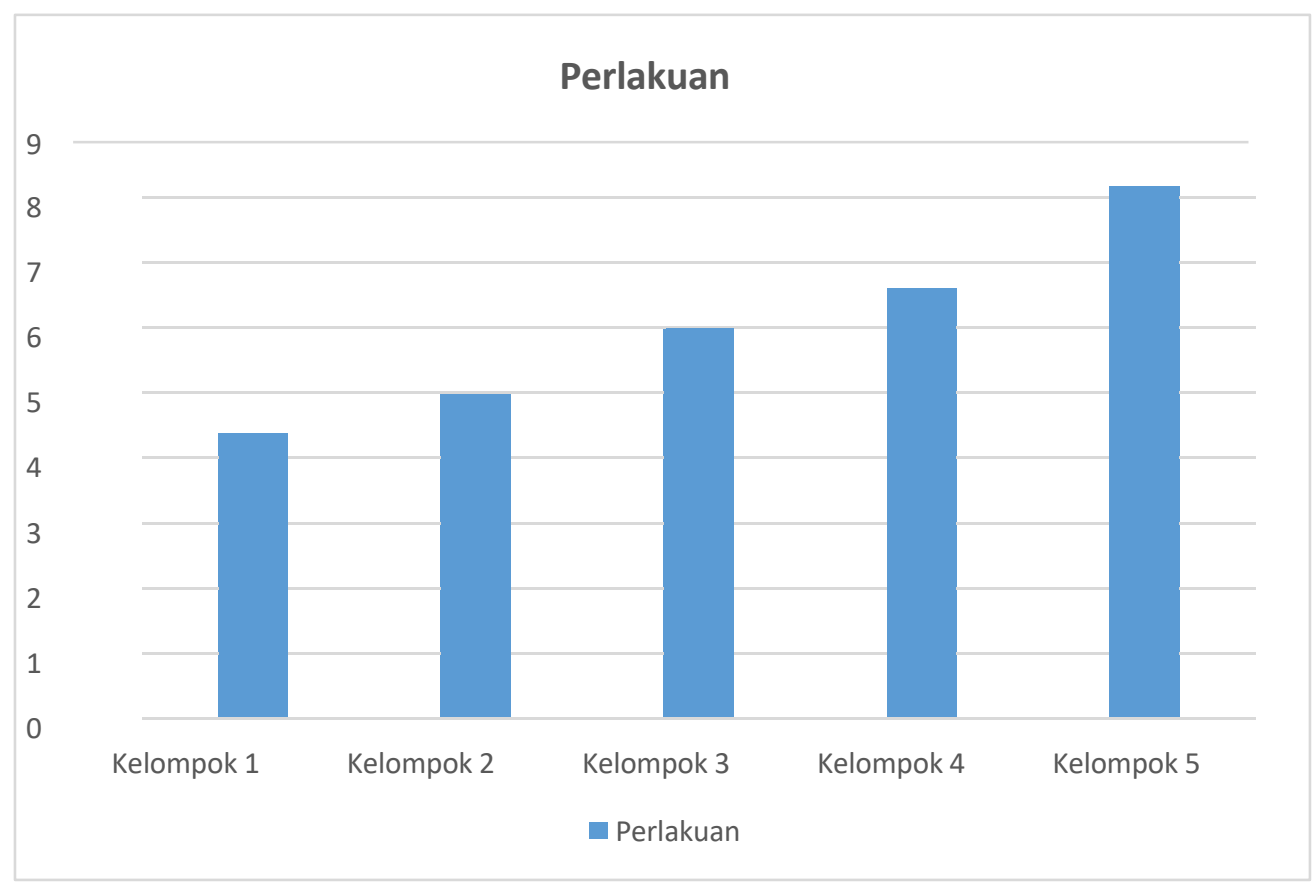

Gambar 1 Diagram Batang Hasil Uji Compressive strength

Berdasarkan diagram di atas menunjukan bahwa uji tekan kompresi yang memperlihatkan nilai compressive strength pada kelompok 1 dengan nilai 4,367 Mpa, kelompok 2 dengan nilai 4,902, kelompok 3 dengan nilai 5,971 $\mathrm{MPa}$, kelompok 4 dengan nilai $6,595 \mathrm{MPa}$, dan hasil uji tertinggi terdapat pada kelompok uji $\mathrm{V}$ dengan nilai rerata $8,161 \mathrm{Mpa}$.

\section{Analisis Statistik Uji Compressive strength}

Berdasarkan data yang terdapat pada tabel I, diperoleh data hasil perhitungan statistik uji

Compressive strength sebagai berikut:

- Uji Normalitas

Uji normalitas digunakan untuk melihat apakah sebaran data berasal dari sebaran yang normal atau tidak. Data dikatakan normal jika nilai $p$-value > 0,05 , dan sebaliknya dikatakan tidak normal jika $p$-value $<0,05$. Berikut adalah hasil uji normalitas uji compressive strength dari masing-masing kelompok.

Tabel II Hasil Uji Normalitas Compressive strength

\begin{tabular}{|c|c|c|}
\hline \multirow[t]{2}{*}{ Kelompok } & Test for Normality* & Test of Homogenity** \\
\hline & Nilai P & Nilai P \\
\hline $0,0 \%$ & 0,798 & 0,330 \\
\hline $0,5 \%$ & 0,575 & \\
\hline $1,0 \%$ & 0,058 & \\
\hline $1,5 \%$ & 0,929 & \\
\hline $2,0 \%$ & 0,762 & \\
\hline
\end{tabular}


Data diuji normalitasnya dengan uji Saphiro wilk, karena pada semua kelompok nilai $\mathrm{p}(\mathrm{sig})>0,05$, dapat disimpulkan sebaran data normal.

- Uji Homogenitas

Tabel III Hasil Uji Homogenitas Compressive strength

\begin{tabular}{llll}
\hline & Kelompok & - & $\frac{\text { Test for Homogenity* }}{\text { Nilai P }}$ \\
\hline $0.0 \%$ & & & \\
& $0.5 \%$ & 0.330 & \\
$1.0 \%$ & & \\
$1.5 \%$ & & \\
$2,0 \%$ & & \\
\hline
\end{tabular}

Data kemudian diuji homogenitasnya, dan menunjukkan nilai $\mathrm{p}(\mathrm{sig}) \quad 0.330$ (>0.05) sehingga dapat disimpulkan data homogen.

- Uji ANOVA One-way

Tabel IV Hasil Uji ANOVA One-Way Compressive strength

\begin{tabular}{llll}
\hline & Kelompok & $\bar{X} \pm S D$ \\
\hline $0.0 \%$ & & & $4.37 \pm 0.51$ \\
$0.5 \%$ & & $4.90 \pm 0.70$ \\
$1.0 \%$ & & $5.97 \pm 0.45$ \\
$1.5 \%$ & & $6.60 \pm 0.32$ \\
$2.0 \%$ & & $8.16 \pm 0.41$ \\
\hline & Nilai p Anova* & 0.000 &
\end{tabular}

Karena data normal dan homogen, uji statistik dapat dilanjutkan dengan One-Way ANOVA. Hasil nilai p (sig.) adalah $0.000(\mathrm{p}<0.05)$ sehingga dapat disimpulkan terdapat perbedaan nilai compressive strength yang signifikan antar kelompok uji dan H0 berhasil ditolak. Data kemudian diolah dengan uji post hoc Tukey untuk mengetahui kelompok mana yang memiliki perbedaan nilai yang signifikan.

- Uji Post Hoc Tuckey

Hasil tes post hoc tuckey menunjukkan bahwa kelompok 5 (kadar nanoselulosa 2\%) memiliki perbedaan nilai compressive strength yang signifikan dengan kelompok lainnnya.

\section{Diskusi}

Kalsium Fosfat adalah salah satu jenis dari bone cement selain dari PMMA karena 
CPC yang memiliki susunan kimawi yang mirip dengan komposisi tulang asli seperti kalsium fosfat jenis hidroksiapatit dan umumnya biokompatibilitas yang baik. Kalsium fosfat seringkali digunakan sebagai bone cement dalam aplikasi kedokteran karena memiliki sifat kemampuan mengeras sendiri (self-hardening), osteokonduktif, biokompatibilitas, bioresorbabel dan mudah dibentuk. Bone cement berbasis kalsium fosfat ini memiliki keterbatasan yaitu tidak dapat menahan beban yang tinggi tetapi kekurangan ini dapat ditanggulangi dengan penambahan filler. ${ }^{4,43}$

Hidroksiapatit menghasilkan struktur mikroporositas dan makroporositas yang serupa dengan tulang manusia. Hidroksiapatit juga memiliki sifat osteoconductive yaitu, memiliki kemampuan untuk mendukung pertumbuhan dan pembentukan jaringan tulang. Tetapi hidroksiapatit memiliki kekuatan yang rendah dan sangat rapuh. Oleh sebab itu perlu adanya penambahan material lain sehingga dapat memperbaiki kekurangannya. Material tambahan tersebut harus cukup elastik, non toksik, dan biodegradabel. Bahan yang menjadi kandidat tersebut adalah material polimer. Salah satu bahan polimer yang dapat memenuhi fungsi tersebut adalah alginat. 44

Filler yang digunakan pada penelitian ini adalah nanoselulosa kristalin dan kitosan sebagai pengikat antara nanoselulosa kristalin dengan kalsium fosfat.

Nanoselulosa kristalin pada penelitian ini disintesa menggunakan metoda hidrolisis asam menggunakan asam sulfat $\left(\mathrm{H}_{2} \mathrm{SO} 4\right)$ temperatur yang digunakan lebih rendah, dan waktu proses yang lebih cepat, sehingga mampu melarutkan lignin dan hemiselulosa pada prekusor sampai didapatkan nanoselulosa kristalin, dan pada penelitian ini serat nanas digunakan sebagai prekusor. Serat nanas seringkali digunakan sebagai sumber nanoselulosa kristalin karena memiliki kadar hemiselulosa, selulosa, dan lignin yang menjadikannya sebagai biomassa pembentuk selulosa yang baik, terlebih serat nanas memiliki kadar selulosa sebanyak $70 \%$ sehingga diproduksi cukup banyak dalam industri. ${ }^{45}$

Filler yang telah disintesa selanjutnya dikarakterisasi dengan tujuan melihat ukuran partikel dan morfologinya. Nanoselulosa kristalin dikarakterisasi menggunakan TEM dan XRD. Hasil karakterisasi TEM terhadap nanoselulosa kristalin yang dihasilkan menggunakan metoda hisrolisis asam memiliki ukuran berkisar 134 sampai $407 \mathrm{~nm}$ dengan perbesaran 15.000 kali dan 30.000 kali.

Hasil karakterisasi XRD nanoselulosa kristalin menunjukkan puncak-puncak yang menggambarkan kristalinitas pada difaktogram. Semakin sempit dan tajam suatu puncak, maka akan semakin tinggi derajat kristalinitas suatu material, namun jika semakin besar akan semakin baik sifat mekanis material tersebut. Indeks kristalinitas yang rendah menghasilkan struktur yang elastis, sehingga nanoselulosa dengan indeks kristalinitas rendah dapat dimanfaatkan untuk membuat produk yang fleksibel dan tidak mudah fraktur. Sebaliknya Indek kristalinitas yang tinggi menunjukkan bahwa bagian kristalin dengan susunan yang teratur lebih dominan daripada bagian amorf yang memiliki susunan tidak teratur. Indeks kristalinitas tinggi menghasilkan struktur yang kaku atau rigid.

Terdapat lima kelompok, yaitu kelompok I ( CPC tanpa adanya penambahan nanoselulosa), kelompok II ( CPC dengan penambahan nanoselulosa 0,5\%), kelompok III ( CPC dengan penambahan nanoselulosa 1\%), kelompok IV ( CPC dengan penambahan nanoselulosa 1,5\%), kelompok V ( CPC dengan penambahan nanoselulosa $2 \%$ ). 
Rerata hasil uji compressive strength pada kelompok 1 adalah 4,36 Mpa, kelompok II adalah 4,90 Mpa, kelompok III adalah 5,97, kelompok IV adalah 6,59 Mpa, kelompok V adalah 8,16 Mpa. Pada kelompok V didapatkan nilai rerata yang paling tinggi dibandingkan kelompok lainnya yang diberikan lebih sedikit filler daripada kelompok V. Hal ini menunjukkan penambahan filler nanoselulosa kristalin mampu meningkatkan sifat mekanis kalsium fosfat dan kitosan yang bertindak sebagai pengikat antara kalsium fosfat dan filler nanoselulosa kristalin mampu mendukung kekuatan sifat mekanisnya.

Menurut referensi standar ISO 5833, nilai compressive strength dari cement bone adalah $70 \mathrm{Mpa}$, sedangkan pada penelitian ini nilai compressive strength belum sesuai dengan yang diharapkan dimana nilai uji compressive strength yang tertinggi adalah 8,16 Mpa (kelompok uji V).

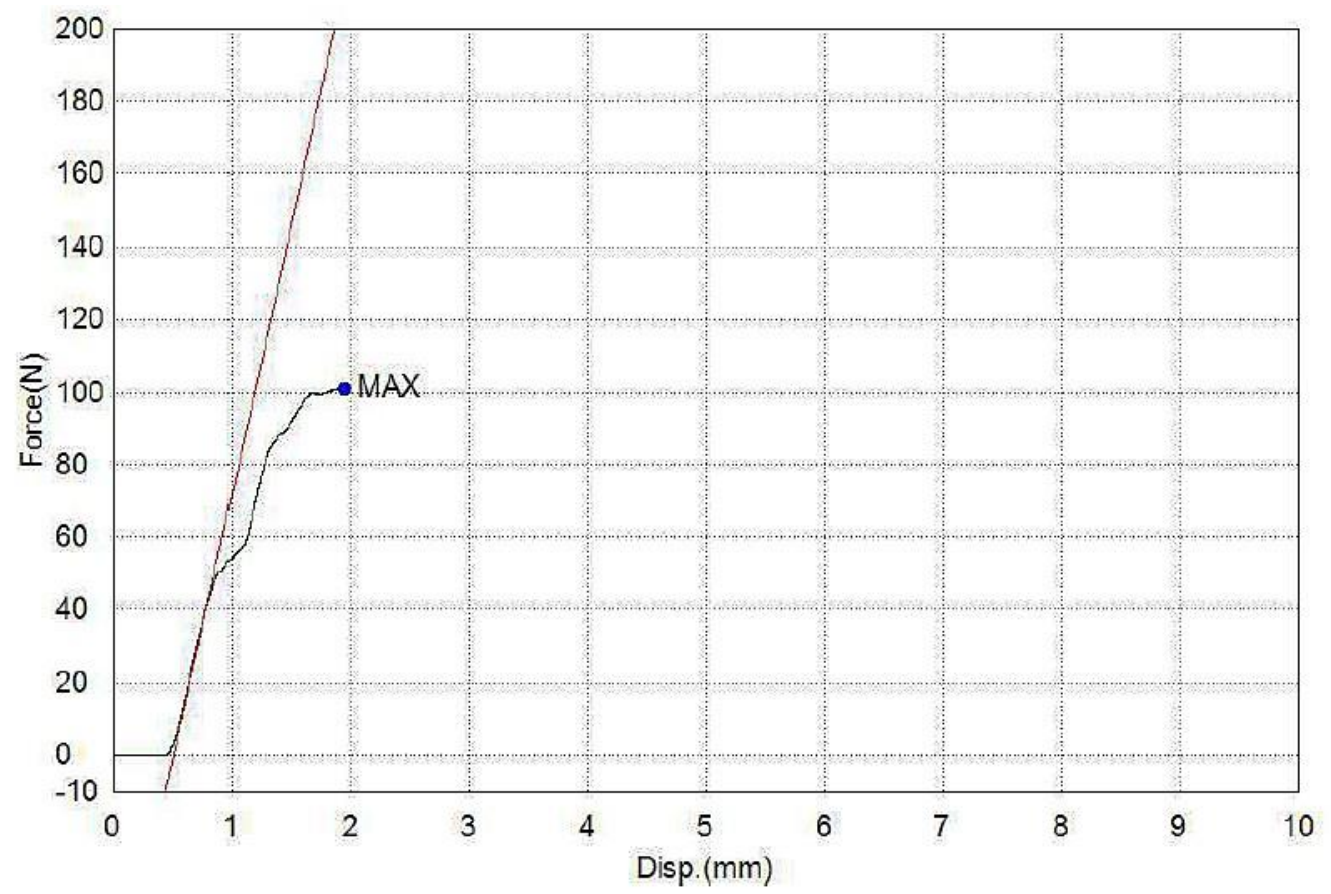

Gambar 2 Grafik Uji Compressive Strength

Dari keterangan grafik hasil uji compressive strength terjadi retakan bertahap, bisa disimpulkan bahwa ketika spesimen diberi beban akan ada bagian yang mengalami keretakan dan kemudian terjadi keretakan dibagian yang lain.

Hal tersebut dapat dikarenakan proses polimerisasi yang kurang baik karena adanya bahan pengotor pada spesimen, dan kurang baiknya proses pencampuran antara matriks, filler dan coupling agent karena pencampuran masih dilakukan secara manual dan kurang homogen, adanya porus karena terperangkapnya udara saat proses pencetakan berlangsung, maupun finishing yang kurang baik sehingga pada pengujian alat uji yang sangat snsitif mendeteksi adanya keretakan pada spesimen. 


\section{Kesimpulan}

Penambahan nanoselulosa kristalin terhadap bone cement berbasis kalsium fosfat dapat mempengaruhi sifat mekanis yaitu compressive strength dengan nilai rerata terbesar 8,16 Mpa (kelompok V).

\section{Referensi}

1. Yihui MA, Rnoli W, Xiangrong C, Zhilan L, Yufeng Z. The behavior of new hydrophilic composite. Bone cements for immediate loading of dental implant. 2013 june;(1):627.

2. Chaushu, Tzohar, \& Dayan. 2011. Immediate Loading of Single-tooth Implants: Immediate Versus Non-immediate Implantation. A Clinical Report

3. Chow L.C, \& Takagi S. A. 2001. Natural Bone Cement-A Laboratory Novelty Led to the Development of Revolutionary New Biomaterials. J Res. Natl. Inst. Stand. Technol. Vol.106, pp. 1029-1033

4. Manoj K \& Karma H.K. 2003. Development of fully injectable Phosphate cement for orthopedic and dental applications. Bull Mater Sci.Vol 26, No.4, pp. 415 - 422.Indian Academy of Science.

5. A. Sinval et al. Flexural Strength and Moduls of Elassticity of Different Types of Resin- Based Composite. Braz Oral Res 2007;21(1):16-21

6. Sears, F. W., Zemansky, M. W., \& Young, H. D. (1987). UNIVERSITY PHYSICS.Canada: Addison-Wesley Publishing Company, Inc.

7. Peng BL et al. Chemistry and Applications of Nanocrystalline Cellulose and its Derivstes: A Nanotechnology Perspective. The Canadian Journal of Chemical Engineering; Volume 9999, 2011

8. Lin N, Dufresne A. Nanocellulose in Biomedicine: Current Status and Future Prospect. European Polymer Journal; 59 (2014): 302-325

9. Yang Lee $\mathrm{K}$ et al. On the Use of Nanocellulose as Reinforcement in Polymer Matrix Composites. Elesevier Mosby; 105 (2014) 15-27

10. R.Z. LeGeros, Calcium Phosphate-Based Osteoinductive Materials, Chemical Reviews 108(11) (2008) 4742-4753

11. Rasyid, A. 2004. Utilization of Turbinaria Decurrens as One of Rwa Materials of Sodium Alginate. In: B.Sulistyo, E.S.Heruwati,A. Sudrajat, I.G.S Mertha and A.H. Prunomo (eds) International Seminar on Marine and Fisheries. The Agancy for Marine and Fisheries Research, Jakarta: 229-231.

12. Cherian BM, Leao AL, De Souza SF, Costa LMM, De Olyveira GM, Kottaisamy 
SONDE (Sound of Dentistry) Vol 3 No 2

$\mathrm{M}$, et al. Cellulose nanocomposites with nanofibers isolated from pineapple leaaf fibers for medical aplications. Carbohydrate Polymers. 2011;86(4):1790-8. 